\title{
A arte na cena da pandemia
}

The art in the pandemic scene

\section{El arte en el escenario de la pandemia}

\author{
Márcia Costa Rodrigues ${ }^{1}$ \\ Lúcia Teresa Romanholli ${ }^{1}$ \\ Cláudia Regina Ribeiro Pinheiro das Chagas ${ }^{1}$
}

DOI: http://dx.doi.org/10.20435/serie-estudos.v26i58.1597

\begin{abstract}
Resumo: Com as dificuldades advindas desses tempos de coronavírus em um país onde faltam políticas públicas engajadas na preservação da vida, seja humana, seja planetária, são muitos os desafios apresentados, desde a luta pela sobrevivência até a criação de novos modos de ser, fazer, comunicar e, também, novos modos de pesquisar. Especialmente quando se propõe a acompanhar os movimentos dos dentrofora das escolas, nas pesquisas nosdoscom os cotidianos, quando encontros, conversas, escutas e trocas com e entre os praticantespensantes se tornam os personagens conceituais de teses e dissertações. Pretende-se, neste dossiê, narrar algumas experiências tecidas com os fios das histórias e dos desejos das autoras sobre os desvios táticos necessários à manutenção da vida e do trabalho, no âmbito da educação e da cultura, como o desenvolvimento de políticas e projetos culturais, desde o desmonte da cultura, que fez parte do golpe contra o governo legitimamente eleito da presidenta Dilma Rousseff, até a experiência da pandemia advinda do coronavírus. Acontecimentos que atravessaram e modificaram significativamente a vida de todos, mais de um ano depois e talvez para sempre. Um devir que se anuncia na fragilidade da sobrevivência humana, na dificuldade da equidade e da justiça social e na constatação da importância das Ciências e das Artes, tecidas por políticas públicas democráticas, para a sobrevivência digna de todos. Foram experiências e continuam sendo vivências plenas de aprendizagens para educadores, trabalhadores do fazer artístico e para os diversos públicos que interagem por meio das telas. Ampliam-se e tecem-se novas redes educativas, estabelecendo relações e usos diversos na comunicação, na curadoria, na produção, na fruição artística, na crítica e no fortalecimento dos elos educativos e culturais que formamos e onde somos formados. São experiências que permeiam as práticas curriculares da escola e muitas redes que transbordam os cotidianos acadêmicos com outros usos, novas fruições e diversos modos de ensinaraprender.
\end{abstract}

Palavras-chave: arte; educação; redes.

Abstract: Nowadays, in difficult times of coronavirus in a country where there is a lack of public policies engaged in the preservation of life, whether human or planetary, there are many challenges presented, from the fight for survival to the creation of new ways of being, doing, communicating, and also new ways of researching. Especially when we propose to follow inside and outside of school

${ }^{1}$ Universidade do Estado do Rio de Janeiro (UERJ), Rio de Janeiro, Rio de Janeiro, Brasil. 
movements, with the researches about everyday life, when meetings, conversations, listening, and exchanges with and among the thinking practitioners become the conceptual characters of theses. It is intended, in this dossier, to report some experiences woven with the threads of the stories and desires of the authors about the necessary tactical deviations to the maintenance of life and work, in the scope of education and culture, as the development of cultural policies and projects, since the dismantling of culture, which was part of the coup against the legitimately elected government of the president Dilma Rousseff, until the experience of the pandemic arising from the coronavirus. Events that crossed and significantly modified the lives of all, more than a year later and perhaps forever. A becoming that announces itself in the fragility of human survival, in the difficulty of equity and social justice, and in the realisation of the importance of the Sciences and the Arts, woven by democratic public policies, for the dignified survival of all. These were experiences and continue to be learning experiences for educators, workers in the making of art, and for the various audiences who interact through the screens. New educational networks are expanded and woven, establishing relations and diverse uses in communication, in curating, in production, in artistic enjoyment, in criticism, and in the strengthening of the educational and cultural links that we form and where we are formed. These are experiences that permeate the curricular practices of the school and many networks that overflow the academic daily life with other uses, new fruition, and diverse ways of teaching-learning.

Keywords: art; education; networks.

Resumen: Con las dificultades en tiempos de coronavirus en un país donde faltan políticas públicas comprometidas con la preservación de la vida, sea humana o planetaria, los desafíos que se presentan son muchos, desde la lucha por la supervivencia hasta la creación de nuevas formas de ser, hacer, comunicar y también nuevas formas de investigar. Sobre todo, cuando se propone seguir los movimientos de los que están dentro y fuera de las escuelas, en las investigaciones en/ con/de los cotidianos, cuando los encuentros, las conversaciones, la escucha y los intercambios con y entre los practicantes del pensamiento se convierten en los caracteres conceptuales de las tesis. Se pretende, en este dossier, narrar algunas experiencias tejidas con los hilos de los relatos y deseos de los autores sobre los necesarios desvíos tácticos para el mantenimiento de la vida y el trabajo, en el ámbito de la educación y la cultura, como el desarrollo de políticas y proyectos culturales, desde el desmantelamiento de la cultura, el cual formó parte del golpe contra el gobierno legítimamente elegido de la presidenta Dilma Rousseff, hasta la experiencia de la pandemia derivada del coronavirus. Sucesos que se cruzaron y cambiaron significativamente la vida de todos, más de un año después y quizás para siempre. Un devenir que se anuncia en la fragilidad de la supervivencia humana, en la dificultad de la equidad y la justicia social y en la constatación de la importancia de las Ciencias y las Artes, tejidas por políticas públicas democráticas, para la supervivencia digna de todos. Fueron y siguen siendo experiencias de aprendizaje para los educadores, los trabajadores del arte y para los distintos públicos que interactúan a través de las pantallas. Se amplían y tejen nuevas redes educativas, estableciendo relaciones y usos diversos en la comunicación, en el comisariado, en la producción, en el disfrute artístico, en la crítica y en el fortalecimiento de los vínculos educativos y culturales que formamos y donde nos formamos. Son experiencias que penetran en las prácticas curriculares de la escuela y en muchas redes que desbordan la cotidianidad académica con otros usos, nuevos frutos y diversas formas de enseñanza-aprendizaje.

Palabras clave: arte; educación; redes. 


\section{INTRODUÇÃO}

Seria criminoso e estúpido colocar os vaga-lumes sob um projetor acreditando assim melhor observá-los. Assim como não serve de nada estudá-los, previamente mortos, alfinetados sobre uma mesa de entomologista ou observados como coisas muito antigas presas no âmbar há milhões de anos. (DIDI-HUBERMAN, 2011, p. 33)

Vaga-lumes? Somos personagens testemunhos de um momento de excepcionalidade histórica, quando máscaras e álcool $70^{\circ}$ passam a fazer parte dos cotidianos, e os encontros humanos, preferencialmente, precisam acontecer por meio de uma tela, sejam aulas, sejam festas, sessões terapêuticas, reuniões familiares ou profissionais. Em uma alusão à experiência da metáfora dos vaga-lumes proposta por Pier Pasolini, revista e costurada poeticamente por Didi-Huberman (2011) com base em outros personagens conceituais, de Dantes a Agamben, considero os vaga-lumes de hoje aqueles e aquelas que resistem acreditando e fazendo acreditar que um mundo melhor é possível e necessário, mesmo em tempos de negacionismo científico, ético e moral, como o que estamos vivendo no Brasil.

Dois mil e vinte foi um ano marcado pelo medo advindo de um vírus, modificando radicalmente a vida humana, identificando nossa fragilidade como espécie no planeta. Dois mil e vinte foi o ano em que nosso país obteve recorde de queimadas, invasão de territórios indígenas ${ }^{2}$ e ausência de políticas públicas a favor da vida. Ademais, 2020 foi o ano em que nós, autores deste trabalho, encontramo-nos no doutorado do Programa de Pós-Graduação em Educação da Universidade do Estado do Rio de Janeiro (ProPEd/UERJ), com o propósito de pesquisar redes educativas que se formam além da sala de aula. Pretendíamos narrar nossas experiências profissionais diversas, como o desenvolvimento de políticas e projetos culturais, a significativa atuação das mulheres nos recentes movimentos políticos brasileiros e o uso das tecnologias nos processos educativos, identificando seus desdobramentos e acompanhando as ações e as histórias dos personagens envolvidos. Mas um forte acontecimento no sentido deleuziano (SOUSA DIAS, s.d., p. 32) atravessou o nosso caminho e o de toda a humanidade. E agora nos vemos comemorando e reinventando a nossa existência, relações e

${ }^{2}$ Informações obtidas no site https://redebrasilatual.com.br 
proposta de trabalho. Como fazer pesquisa nosdoscom os cotidianos ${ }^{3}$ a distância? Como encontrar os personagens conceituais e acompanhar suas histórias e relações? Como tecer novos modos de ser, estar e se relacionar? Esses são alguns dos desafios das pesquisas com os cotidianos no tempo presente que nos motivaram a escrever este dossiê, tecido com os fios das histórias e dos desejos de cada um dos autores.

Para conhecer os vaga-lumes, é preciso observá-los no presente de sua sobrevivência: é preciso vê-los dançar vivos no meio da noite, ainda que essa noite seja varrida por alguns ferozes projetores. Ainda que por pouco tempo. Ainda que por pouca coisa a ser vista: é preciso cerca de cinco mil vaga-lumes para produzir uma luz equivalente à de uma única vela. (DIDIHUBERMAN, 2011, p. 33).

Essa foi a provocação lançada nos encontros do curso "Questões teórico-epistemológicas de pesquisas nosdoscom os cotidianos" ${ }^{\prime 4}$, com base na bibliografia proposta, nas leituras indicadas e, principalmente, nas conversas decorrentes que se transformaram em vaga-lumes nessa escuridão em que estamos vivendo. Aguardávamos a chegada das quartas-feiras, na expectativa de alimentar nossa anima, conhecer melhor os personagens conceituais dessa linha de pesquisa e começar a reorganizar nossos projetos.

Uma das autoras trouxe como proposta inicial o desejo de pesquisar a experiência de ter participado da construção de uma política nacional do âmbito da cultura, dentro de uma instituição de serviço social. A intenção seria refletir sobre a tessitura de algumas redes educativas entre profissionais da educação não formal que realizam projetos de fomento, mediação e formação artística e como essas redes se relacionam com artistas, estudantes, escolas, palcos e plateias, produzindo outros modos de fazer, assistir, aprenderensinar ${ }^{5}$ e viver. Como ponto de partida, trouxemos o trabalho realizado na coordenação das ações do Programa Cultura do Serviço Social do Comércio (SESC) ${ }^{6}$ - Administração Nacional,

3 Pesquisas que consideram o cotidiano como espaçotempo de criação de conhecimento e de produção da vida social [...] (FERRAÇO, 2018, p. 10).

${ }^{4}$ Disciplina ministrada pelas professoras Conceição Soares e Mailsa Passos, PROPED/UERJ, 1은 sem. 2021.

${ }^{5}$ Algumas palavras juntas e em itálico que aparecem neste texto são referências às pesquisas nos/ dos/com os cotidianos, que buscam romper com algumas falsas dicotomias da modernidade.

${ }^{6}$ O Serviço Social do Comércio (SESC) foi criado em 1946, pelos empresários do setor, para cola- 
no período de 2002 a 2018, pretendendo analisar algumas práticasteorias (ALVES, 2021) vivenciadas, especialmente os processos de construção e implantação da política cultural da instituição. Como cenário dessa versão de uma história, trouxemos outro acontecimento, com o atravessamento do golpe ${ }^{7}$, impeachment da presidenta Dilma Rousseff, em 31 de agosto de 2016.

No atropelamento do coronavírus e a partir das reflexões das aulas praticadas, a proposta foi ampliada nos encontros do grupo de pesquisa com novos e outros modos de fazer dos personagens envolvidos, instituições, professores, estudantes, ativistas, artistas e públicos, nas suas reinvenções e fruições virtuais. Outros vaga-lumes que continuam desenvolvendo ações educativas e culturais, tendo como pano de fundo os cotidianos das escolas, sempre mediados pelos usos das tecnologias. O acompanhamento das lives passou a ser uma experiência de pesquisa significativa. Se tudo começou muito confuso, pois, logo no início da pandemia, os professores e estudantes não sabiam como acessar as plataformas e as dificuldades eram muitas, durante o processo, todos foram se ajudando, tudo foi se resolvendo. Como apontam as pesquisas nosdoscom os cotidianos, os usos criam saídas, novas maneiras de resolver, e tudo acontece. Com as experiências on-line, existe a possibilidade de que tudo mude no ensino formal. Quando houver o retorno para a educação presencial, as tecnologias de mídias, como celulares, principalmente, pois seu uso era proibido nas salas de aula, deverão ter outro tratamento, e os professores, provavelmente, retornarão com outros modos de sentirfazerviver.

A questão dos vaga-lumes seria, então, antes de tudo, política e histórica. Jean-Paul Curnier, que não deixou de evocar a carta de 1941, diz, justamente, num artigo sobre a política pasoliniana, que a beleza inocente dos jovens de Bolonha não denota em nada 'uma simples questão de estética e de forma do discurso, (uma vez que) o que está em jogo ali é capital. Trata-se de extrair o pensamento político de sua ganga discursiva' e de atingir, dessa maneira, esse lugar crucial onde a política se encarnaria nos corpos, nos gestos e nos desejos de cada um. (DIDI-HUBERMAN, 2011, p. 15).

borar no cenário social, com ações nas áreas de Educação, Cultura, Saúde, Assistência e Lazer. Ele existe hoje, em todos os estados brasileiros, com unidades em 580 cidades, desempenhando um papel importante na formação e no fomento artístico e cultural do país.

${ }^{7}$ Disponível em: https://brasil.elpais.com/brasil/2016/08/31/opinion/1472650538_750062.ns 
A proposta agora é costurar as condições de realização, os interesses diversos, os entraves institucionais, econômicos e políticos, com as tensões existentes na correlação de forças entre os múltiplos cenários e atores sociais. O maior desafio será perceber a complexidade das relações dos sujeitos envolvidos nas diferentes instituições educativas. No caso específico, como interagem, educam e educam-se alguns profissionais que atuam no SESC, na relação entre Departamento Nacional e os Departamentos Regionais, considerando a dimensão federativa da instituição, e na relação deles com as manifestações culturais e com os fazedores das artes brasileiras em cada território, antes, ao longo e depois do impeachment e antes, ao longo e depois da pandemia. Partimos, portanto, da seguinte questão: como se forjam os conhecimentossignificações nesse dentrofora institucional e resultam em documentos, currículos, políticas e práticas, culturais e educativas, em tempos de pandemia?

Essas pesquisas aproximam-se dos estudos cotidianos pela necessidade de entender o que transborda, o que vai além no dia a dia dos processos instituídos e formalizados, identificando também o que ficou de fora, o não dito, as outras possibilidades de contar uma história. Não é suficiente, apesar de necessário, narrar os modos de produção de um documento conceitual e normativo. É fundamental entender quem são e como operam os sujeitos, personagens conceituais, e as relações envolvidas, para além do que ficou formalizado. Ademais, conhecer a multiplicidade de fazeres e significações decorrentes, especialmente em momentos de excepcionalidade. O que aconteceu e acontece com os projetos artísticos e culturais ante o impeachment e durante a pandemia.

\section{A ARTE E O COMBATE DE UMA HISTÓRIA ÚNICA}

Arte e vida não são a mesma coisa, mas devem tornar-se algo singular em mim, na unidade da minha responsabilidade. (BAKHTIN, 2010, p. 34).

Falamos de resistência quando estamos sob ataque. Analisando que o decréscimo dos vaga-lumes é o resultado da pressão contra a arte e a cultura, podemos considerar que a cruzada contra as artes não se origina com o golpe, mas se institui com o processo de deslaicização do Estado, que, na verdade, nunca foi laico. Esse recrudescimento das religiões pentecostais, esse crescimento da ideia de uma pureza, de uma sociedade que precisa limpar-se dos pecados, põe o 
artista como o grande acusado de ser esse o criador e incentivador da derrocada moral do Estado Nacional.

Uma das primeiras iniciativas do governo do presidente interino Michel Temer, em maio de 2016, ainda no início do processo do golpe, foi a tentativa de extinção da pasta da cultura, resultando na ocupação do Palácio Capanema, onde funcionava a Fundação Nacional de Artes (Funarte), prédio modernista, no centro do Rio de Janeiro, que, no passado, abrigou o Ministério da Educação. Logo em seguida, houve também a ocupação do Canecão, importante casa de shows. Capanema e o Canecão são simbólicos na nossa cultura, são dois espaçostempos de representação da cidade do Rio de Janeiro em suas mais diversas manifestações culturais vaga-lumes do nosso país. Participaram da ocupação coletivos do audiovisual, movimento Teatro pela Democracia, Pontos de Cultura, Programa Cultura Viva, representantes do circo, da música, da poesia e do teatro. Eram centenas de jovens numa ocupação autogestiva, num pisca-pisca de criação de arte e cultura, que, logo em seguida, nos contaminou com a ideia de ocupação das escolas do Rio de Janeiro, dando visibilidade às redes que formamos e nos formam no emaranhado da educação e da cultura.

Todos nós, nesses diferentes 'espaçostempos', somos 'marcados' pelas relações que mantemos com muitos outros 'praticantespensantes' em múltiplos e complexos 'mundos culturais' (Augé, 1997; Alves, 2014) que nessas redes são criados e recriados. (ALVES, 2019, p. 115).

Em 2020, a exoneração do secretário nacional da Cultura, Roberto Rego Pinheiro, conhecido como Roberto Alvim, que fez um discurso no qual usou frases semelhantes às usadas por Joseph Goebbels ${ }^{8}$, ministro da Alemanha durante o governo nazista, provocou muita pressão num piscar de vaga-lumes em faróis altos após o discurso com frases semelhantes às do ministro de Hitler. Alvim, assim como Goebbels, havia afirmado, em meados do século XX, que a "arte alemã da próxima década será heroica" e "imperativa". Alvim afirmou que a "arte brasileira da próxima década será heroica" e imperativa". Os ataques à cultura e também à educação são indícios do clima de ódio, de desagregação cultural de perseguição e intolerância às diferenças.

\footnotetext{
${ }^{8}$ Ministro da Propaganda da Alemanha Nazista, Joseph Goebbels, antissemita radical e um dos idealizadores do nazismo.
} 
O Programa Escola sem Partido $^{9}$ e as inúmeras iniciativas de destruição das diferentes manifestações artísticas e culturais são um dispositivo que tem por projeto restringir as redes educativas que nos formam, mas, nos múltiplos possíveis entrelaces das redes, surgem encontros potenciais que formam vaga-lumes de emancipação. Não é à toa, não é por coincidência que um projeto de extinção da pasta da Cultura transita com a proposta da "tal" Escola sem Partido. Como nos diz Peter Pal Pelbarti (2018), uma guerra contra os movimentos de criação, de emancipação. E essa guerra é uma guerra tipo terra arrasada. Ela é contra a cultura, é contra a informação. O ataque à cultura é uma estratégia de ceifar a criação. Sufoca-se a cultura, e a memória, numa ação de extrema violência, faz-me lembrar o que fizeram com os índios, as guerras colonizadoras:

Estamos em guerra. Guerra contra os pobres, contra os negros, contra as mulheres, contra os indígenas, contra os craqueiros, contra a esquerda, contra a cultura, contra a informação, contra o Brasil. A guerra é econômica, política, jurídica, militar, midiática. É uma guerra aberta, embora denegada; é uma guerra total, embora camuflada; é uma guerra sem trégua e sem regra, ilimitada, embora queiram nos fazer acreditar que tudo está sob a mais estrita e pacífica normalidade institucional, social, jurídica, econômica. (PELBARTL, 2018, p. 190).

A tentativa de isolar as ações dos praticantespensantes dessas áreas é uma tentativa de impedir a formação das redes, mas as redes são rizomas. A rede é rizoma. Ela expande-se no movimento de procura de outros nós e torna-se mais potente. Ela é o inesperado, o que foge ao controle e à censura. É pensamento, fruição, criação.

Nas redes, pipocam ali e aqui, nas mais diversas criações, que, num movimento de respiro, procura de ar, sobrevoam, na busca dos pisca-piscas dos vaga-lumes, pequenas lanternas em meio à tamanha escuridão. É o cintilar de resistências ziguezagueando por aí...

$\mathrm{Se}$, a cada dia, parece que estamos derrotados, um incômodo se faz e somos levados a pensar de outra forma. A derrota incomoda e nos faz sair do lugar. Movimento. É preciso fazer nascer, proliferar outras sensibilidades que rompam com o silenciamento que nos tentam impor. Fazer do pensamento uma insur-

\footnotetext{
9 Projeto de Lei n. 867/2015, "Programa Escola sem Partido", consiste nas ideias do Movimento Escola sem Partido em forma de Lei.
} 
gência, uma conspiração cotidiana. Experienciar e desinvibilizar os ziguezagues num olhar para o que resiste, desvia, desnormatiza, criando outras possibilidades.

A arte expressão outra que, na sua multiplicidade, cria muitos, muitas, faz fluir possibilidades outras, e, em seu contexto educacional, como disciplina curricular, a arte também é perseguida.

Entre rasgos e rupturas, trabalhando com as narrativas de pessoas comuns (CERTEAU, 2000) e considerando-as como documentos históricos que atualizam o passado, conferindo-Ihe sentido com as marcas do presente, faz-nos pensar que o fazer histórico, por muito tempo, ancorou-se em versões oficiais sobre os acontecimentos, cujas fontes remetem aos interesses dos atores em cena - geralmente privilegiando o ponto de vista daqueles que se mostram como os "vencedores". Tal prática produziu a ideia de uma história única e linear que servia para legitimar certo estado de coisas, posições, dominações. Cada tempo histórico é marcado por uma epistemologia, e essa marca costuma ditar os procedimentos praticados pelos pesquisadores.

Trazendo esse tempo agora em que um professor de artes é exonerado de seu trabalho, ao levar para trabalhar com seus alunos do 9o ano, em sala de aula, um clipe que tratava de assunto relacionado à diversidade e também ao tema do movimento LGBTQIA+. Vale ressaltar que o clipe da música "Etérea", assim como o documentário, circula nas redes sociais sem nenhum tipo de restrição e já foram exibidos pelo mundo, inclusive na Filmoteca da Universidade Nacional do México e em diversas instituições de dança, arte e música, até mesmo em festivais de cinema, afirmando, na letra de Criolo ${ }^{10}$, que é "necessário quebrar os padrões e abrir discussões".

Uma bala quase hétero

Etérea, massa, complexo

De não se entender

Um canalha quase hétero

Ignorar e amor por complexo

Medo de nele se ver

É necessário quebrar os padrões

É necessário abrir discussões

Alento pra alma, amar sem portões

Amores aceitos sem imposições

${ }^{10}$ Criolo é um cantor, rapper, compositor criado no Grajaú, periferia da Cidade de São Paulo, que, por 12 anos, foi professor de Artes em escolas. 
Singulares, plural

Se te dói em ouvir

Em mim dói no carnal

Mas se tem um jeito esse meu jeito de amar

Quem lhe dá o direito de vir me calar?

Eu sou todo amor, medo e dor se erradicar

Feito sol que ilumina a umidade suspensa do ar.

Homo, homo, homo

Homo, homo, homo

Homo, homo, homo

Homo sapiens errou

Homo, homo, homo

Homo, homo, homo

Homo, homo, homo

Homo sapiens errou

Uma bala quase hétero

Etérea, massa, complexo

De não se entender

Um canalha quase hétero

Ignorar e amor por complexo

Medo de nele se ver

É necessário quebrar os padrões

É necessário abrir discussões

Alento pra alma, amar sem portões

Amores aceitos sem imposições

Singulares, plural

Se te dói em ouvir

Em mim dói

Mas se tem um jeito esse meu jeito de amar

Quem Ihe dá o direito de vir me calar?

Eu sou todo amor, medo e dor se erradicar

Feito sol que ilumina a umidade suspensa do ar

Homo, homo, homo

Homo, homo, homo...

Homo, homo, homo

Homo sapiens errou

Homo, homo, homo

Homo sapiens errou.

O ambiente nas inúmeras redes de ensino é de tensão. Especula-se que os diretores de escolas recebam orientações para tratar desses "assuntos" com 
maior atenção. Em meio aos professores, há manifestações veladas de apoio ou de rejeição, mas muita cautela. Imperam o medo, a ameaça.

É possível, entre inúmeras hipóteses, concluir que, apesar de vivermos em um período dito democrático, o recrudescimento das forças sociais conservadoras no momento contemporâneo tem suscitado um novo processo de perseguição docente no interior das instituições escolares. O pano de fundo é a disputa entre projetos de formação humana, evidenciando a educação escolar como espaço contraditório, podendo também servir como espaço de conscientização e emancipação das camadas populares. Em ambos os processos, o trabalho docente crítico-reflexivo é um elemento central. Nosso tempo é um agora com resquícios de um ontem que teima em se fazer presente.

A história única cria estereótipos, e o problema com os estereótipos não é que sejam mentira, mas que são incompletos. Eles fazem com que uma história se torne a única história. (ADICHIE, 2019, p. 14).

O problema para Adichie é que, ao criar estereótipos, estes superficializam a experiência e negligenciam todas as outras narrativas que formam um lugar ou uma pessoa. Produz-se uma parcialidade negando os outros, "[...] eles transformam uma história na única história" (ADICHE, 2019, p. 21).

\section{A ARTE EM MÚLTIPLAS CENAS}

Quando Pasolini anuncia que 'não existem mais seres humanos' ou quando Giorgio Agamben, de seu lado, anuncia que o homem contemporâneo se encontra 'despossuído de sua experiência', nós nos encontramos, decididamente, colocados sob a luz ofuscante de um espaço e de um tempo apocalípticos. (DIDI-HUBERMAN, 2011, p. 49).

Para não nos deixarmos ofuscar e desaparecer na luz apocalíptica da falta de políticas públicas no enfrentamento de uma pandemia, precisamos falar sobre esse vivido. Precisamos conhecer, ouvir, pesquisar, registrar e ressignificar essas histórias como condição de sobrevivência e de existência. Em 13 de março de 2020, fechamos, assustados, as portas das 19 Unidades do SESC Rio. Na véspera, em uma reunião com diversos gestores de espaços culturais da cidade, algumas associações representativas de artistas e secretários de Saúde e de Cultura do Estado e do Município do Rio de Janeiro, foi evidenciada essa necessidade em face da chegada do novo vírus no país e dos estragos que ele estava causando em 
outras partes do mundo. Cada instituição procuraria o melhor jeito de fazer isso. "Conclui-se que as 'imagens-vaga-lumes' podem ser vistas não somente como testemunhos, mas também como profecias, previsões quanto à história política em devir" (DIDI-HUBERMAN, 2011, p. 86).

Trata-se de um acontecimento que atravessou e modificou significativamente nossa vida, mais de um ano depois e talvez para sempre, o que poderá comprovar as experiências e pesquisas futuras. Um devir que se anuncia na fragilidade da sobrevivência humana, na dificuldade da equidade e da justiça social e na constatação da importância das Ciências e das Artes, tecidas por políticas públicas democráticas, para a sobrevivência digna de todos.

Senti-me participando de um filme de ficção, quase beirando terror, daqueles em que, em algum momento, todos saem correndo numa mesma direção, com medo, sem saber muito bem onde vão chegar. Mesmo que a orientação fosse "ficar em casa", fazer "isolamento social", a sensação era, e continua sendo, a de uma corrida coletiva, apesar de fisicamente solitária, a favor da vida. Bastaria seguir as recomendações, esperar notícias e orientações que vislumbrassem um final feliz, e tudo voltaria ao normal, com a maior brevidade possível. No inconsciente de quem foi embalada pelos contos de fada e filmes hollywoodianos ${ }^{11}$, aguardava palavras acalentadoras, uma resposta certa, um final feliz. Entretanto, acordava desse estado de fantasia com textos reacionários e genocidas. Continuamos sentindo-nos assim e vivendo uma ficção, mais de um ano depois, especialmente no meio das desorientações de falsos mitos, estapafúrdios e inescrupulosos governantes. Um cotidiano em que a fiç̧ão se mistura com a realidade, se é que alguma vez ela tenha se separado, mas, desta feita, com um roteiro macabro, considerando o número de mortos no Brasil ${ }^{12}$, ainda sem um final feliz. "Ainda" porque temos esperança, pois, nesse mesmo cotidiano, também encontramos saídas, das vacinas às ações solidárias e práticas colaborativas, novas possibilidades de ser e fazer que só fortalecem a importância das pesquisas nosdoscom os cotidianos.

Para isso, precisamos, em nossas pesquisas nos/dos/com os cotidianos, de posturas epistemológicas, teóricas e metodológicas que nos possibilitem, além de indicar os mecanismos de homogeneização e as dinâmicas de

\footnotetext{
${ }^{11}$ Referência às produções cinematográficas norte-americanas, que, desde o início do século XX, vêm alimentando o conceito de indústria cultural (http://institutodecinema.com.br).

12 Brasil atinge 500 mil mortos em 19 de junho de 2021. Dados obtidos em https://saúde.ig.com.br.
} 
exclusão, repressão e controle exercidos supostamente apenas por um poder centralizador e determinista (articulado em diversos contextos, como o político, o econômico, o cultural, o científico, o religioso etc.), enxergar os usos que os praticantes dos cotidianos escolares fazem deles e os desvios que esses usos produzem, instituindo, permanentemente, diferença. Nessa perspectiva, torna-se relevante compreender os cotidianos como campos de luta, nos quais o poder, como relação de forças, está sempre sendo contestado e disputado. Precisamos, ainda, indicar a multiplicidade de modos de existência e de conhecimentos que, com essas operações de usuários, se engendram e singularizam criando cultura e produzindo sentidos. (FERRAÇO, 2018, p. 79-80).

Esse é o desafio do momento em que vivemos: identificar "[...] a multiplicidade de modos de existência e conhecimentos [...]" (FERRAÇO, 2018, p. 80) engendrados no caos do coronavírus e da desigualdade social, a favor da educação, da cultura e da vida. Nesse caminho, pretendo ultrapassar o pano de fundo das narrativas dos processos de tessitura de uma política cultural nacional e debruçar-me na identificação dos diferentes campos de forças e relações estabelecidas entre os sujeitos praticantespensantes, dos processos instituídos como estratégias de gestão às táticas vivenciadas, identificando modos de sobrevivência de alguns artistas do estado do Rio de Janeiro durante a pandemia em 2020/2021, os usos, as criações e apropriações possíveis realizadas mediante demandas e consignas de instituições que atuam no campo das artes e das culturas, como o SESC.

Cultura é uma prática significativa. 'Ela consiste não em receber, mas em exercer a ação pela qual cada um marca aquilo que outros the dão para viver e pensar' (CERTEAU, 1995, p. 143). Assim, para o autor (p. 142), não há na sociedade setor particular (religião, ideologia, ciência, mercado, mídia etc.) capaz de 'fornecer a todos os outros aquilo que os proverá de significação'. Nessa perspectiva, como assinalou Giard (1995, p. 10), as culturas não constituem um conjunto de valores a serem preservados e defendidos, ao contrário, constituem-se como um trabalho a ser realizado em toda extensão da vida social, o qual 'requer uma atividade, um modo de apropriação, uma adoção e uma transformação pessoais, um intercâmbio instaurado em um grupo social'. A inversão na abordagem em relação a outras práticasteorias difundidas à época consiste na desapropriação da cultura no singular (apagamento da propriedade e do nome próprio) e, simultaneamente, em uma passagem a práticas de significação, isto é, a operações produtoras. (FERRAÇO, 2018, p. 75). 
O SESC trabalha com crianças, jovens, adultos e idosos, o dia todo, todos os dias, com ações de educação, cultura, lazer, saúde e assistência. "Uma instituição que gosta de aglomerar gente ${ }^{13 \prime \prime}$ e, desde o seu início (1946), atua com o desenvolvimento de ações culturais, como estratégia educativa, de transformação social e de aproximação nos territórios onde se instala, abrindo-se para diversas manifestações brasileiras e promovendo sua difusão e fomento. Até 2019, essa instituição, por meio dos "praticantespensantes" que nela atuam, aprendeu a fazer a programação presencial em que músicos, atores, escritores, palhaços, malabaristas, contadores de história, pintores, desenhistas, escultores, performances, cantores, entre tantos outros profissionais das artes, interagiam com diversos públicos, ocupando múltiplos espaços, próprios ou cedidos, praças e ruas de diferentes cidades. Como consequência da pandemia, o SESC Rio teve de se reinventar em um curtíssimo espaço de tempo, transformando seus teatros, galerias, oficinas e cinemas em palcos virtuais nas redes sociais. De março a junho de 2020, realizando teletrabalho, conversamos com os artistas já contratados ou em vias de contratação, suspendendo as programações, mas antecipando o pagamento delas, entendendo a importância disso para eles e buscando novas formas de realizações que não comprometessem a proposta estética, ética e política de seus projetos.

Não conseguimos atender nosso público principal, nem o público infantil de forma significativa, mas conseguimos atender outros públicos que não frequentavam nossas Unidades. O desafio no início era os próprios artistas se adaptando ao virtual. Nosso desafio continua sendo na divulgação e para atingir nosso público. Em 2020 adaptamos todas as apresentações para o virtual. A maioria ficou num formato simples de apresentação. Não encontramos medos ou resistências, mas todos estavam também se adaptando para o novo formato. (Depoimento de lara Costa, Analista de Biblioteca do Sesc RJ ${ }^{14}$.

O caminho de utilização da tela, do uso das redes sociais para a realização das atividades, começou a ser utilizado por outras áreas e apresentado como solução estratégica para a instituição. Surgiram lives de todos os formatos e assuntos. Mas como fazer isso com as apresentações artísticas? Como transformar em digital a

13 Declaração da Diretora do SESC Rio de Janeiro, doutora Regina Pinho, durante uma reunião virtual com diretores e gerentes, em 10 de março de 2021, transmitida via Teams.

${ }^{14}$ Entrevista concedida por WhatsApp, em 08/08/2021, como parte da pesquisa para compor este trabalho. 
arte que se faz no encontro dos corpos, que se manifesta no calor da emoção dos sentimentos humanos? Ainda seria arte? O que é arte? Para que serviria a arte diante do medo da morte? Teríamos público? Precisávamos reinventar outros modos de realizar programações culturais que não dependessem do encontro físico entre palco e plateia, artistas e públicos.

$\mathrm{O}$ artista e o homem estão unificados em um indivíduo de forma ingênua, o mais das vezes mecânica: temporariamente o homem sai da 'agitação do dia-a-dia' para a criação como para outro mundo de 'inspiração', sons doces e orações: o que resulta daí? A arte é de uma presunção excessivamente atrevida, é patética demais, pois não lhe cabe responder pela vida que, é claro, não lhe anda no encalço. 'Sim, mas onde é que nós temos essa artediz a vida -, nós temos a prosa do dia-a-dia'. (BAKHTIN, 2010, p. 33).

Com pouco contato e acesso às tecnologias que poderiam colaborar para essas novas possibilidades, tivemos de ultrapassar as formas instituídas das relações padronizadas entre as equipes do SESC, gestores, analistas, curadores, profissionais das áreas de comunicação e de tecnologia da informação, para, com os produtores, artistas, cenógrafos, músicos e escritores, nos reinventarmos. Esse foi o grande desafio "[...] da prosa do dia-a-dia [...]" (BAKTIN, 2010, p. 33)) no início e durante toda pandemia, conversando com todos, refletindo sobre possibilidades, experimentando diferentes caminhos, aprendendo juntos. "A arte é uma presunção excessivamente atrevida [...]" (BAKTIN, 2010, p. 33). E nasceu o Arte em Cena, um projeto desenvolvido por muitas mãos, vozes e ideias, com o objetivo de criar um palco virtual, para que as programações culturais pudessem continuar acontecendo, apesar do "isolamento social" decretado no município e em todas as outras 91 prefeituras que fazem parte do estado do Rio de Janeiro.

A partir de 9 de junho de 2019, assumimos um palco no YouTube ${ }^{15} \mathrm{com}$ programações semanais de teatro, dança, circo, música e literatura, apresentações e mediações para crianças, jovens e adultos. Em 2020, ampliamos a proposta com ações de artes visuais e audiovisuais: exibições de filmes, exposições virtuais e debates. Até maio de 2021, foram realizadas 354 apresentações, atingindo 97.964 visionamentos ${ }^{16}$. Para além dos números, até porque não podemos estabelecer

\footnotetext{
${ }^{15}$ Disponível em: https://www.youtube.com/results?search_query=arte+em+cena+sesc+rj

${ }^{16}$ Dados obtidos em relatórios internos do SESC RJ, frequentemente atualizados no site www. sescrio.org.br
} 
uma relação biunívoca entre visionamentos e pessoas, entendemos que criamos uma janela para os artistas, a maioria do estado do Rio de Janeiro, comunicarem-se com o mundo. Muitos vaga-lumes que se encontraram continuam se encontrando e, apesar das dificuldades, reinventam-se com novos modos de fazer, interpretar, cantar, tocar, ler histórias, interagir e assistir.

Não creio que houve perda com o Arte em Cena. Ao contrário, ele foi um ganho, na medida em que o SESC RJ encontrava-se ainda tateando sobre o que fazer no cenário virtual. Os desafios em relação a esse campo estavam postos para a instituição há tempos. Somente na pandemia é que houve a compreensão de que não dava mais pra não pensá-lo como também um meio ativo de estar no mundo. Já os desafios que o Arte em Cena trouxe foram o de nós, enquanto analistas, nos entendermos com as telas, na aparição mesmo, colocando o rosto para o mundo, assim como estudar sobre aquilo que funciona para cada público, não esquecendo nunca também daquilo que é necessário ser falado, apresentado para esse mesmo público, a despeito dos interesses. (Depoimento de Moises Nascimento, Analista de Literatura do Sesc RJ). ${ }^{17}$

Ao acompanhar o cotidiano dessas histórias, não pude deixar de alinhavá-las com os fios tecidos nos encontros das aulas do doutorado ProPEd/UERJ, quando encontrei novas formas de olhar, identificando a potência desses bastidores com a potência da vida: necessidades, dificuldades, medos, possibilidades e aprendizagens; resistências e resiliências que nos mantêm vivos.

Escapando às totalizações imaginárias do olhar, existe uma estranheza do cotidiano que não vem à superfície, ou cuja superfície é somente um limite avançado, um limite que se destaca sobre o visível. Nesse conjunto, eu gostaria de detectar práticas estranhas ao espaço 'geométrico' ou 'geográfico' das construções visuais, panópticas ou teóricas. Essas práticas do espaço remetem a uma forma específica de 'operações' ('maneiras de fazer'), a 'uma outra espacialidade' (uma experiência 'antropológica', poética e mítica do espaço) e a uma mobilidade opaca e cega da cidade habitada. Uma cidade transumante, ou metafórica, insinua-se assim no texto claro da cidade planejada e visível. (CERTEAU, 2000, p. 172).

Da mesma forma que Certeau (2000, p. 172) detecta “[...] práticas estranhas ao espaço 'geométrico' ou 'geográfico' das construções visuais, panópticas ou

17 Entrevista concedida por WhatsApp, em 09/08/2021, como parte da pesquisa para compor este trabalho. 
teóricas [...]", arrisco buscar outros modos de perceber e sentir um pouco do experimentado no SESC RJ, no meio da pandemia, conversando, ouvindo outras vozes e provocando alguns estranhamentos. Por isso, também trouxe para colaborar na tessitura deste texto fragmentos de conversas com companheiros de trabalho.

Sem dúvidas, a maior perda para as Artes Cênicas foi a falta da relação direta e a troca presencial com o público. As Artes Cênicas são conhecidas como a arte da presença, aquelas que se constroem para e com o público e a questão do distanciamento social impôs esse grande desafio para os criadores da linguagem. Especialmente no circo, onde são raras as experiências em caixa preta e quarta parede, a ação depende diretamente do retorno do público para o desdobramento da performance. Sinto que o primeiro movimento dos artistas das artes performativas no início da pandemia foi explorar os recursos da plataforma Zoom, que permitia em alguma instância manter a experiência do ao vivo, com possibilidades de erros e improvisos como na experiência presencial e também permitia a valiosa possibilidade de interação com o público. Logo depois, surgiram o que muitos têm chamado de 'peças-filme' que garantem uma outra experiência, mais próxima do audiovisual, com um cuidado técnico apurado e que substitui o foco do refletor pelo recorte da câmera que direciona o olhar do público. Surgiram também movimentos com pesquisa direcionada a outras experiências sensoriais, focadas no trabalho de voz do ator e nas imagens que as artes cênicas criam através do texto e da corporeidade. Acredito que o desenvolvimento de pesquisas das linguagens e o fato de reconhecer a câmera como público tenha sido um processo de aprendizado que permitiu os artistas expandirem suas possibilidades de atuação e criarem pontes com outros artistas. (Depoimento de Fabiana Villar, Analista de Artes Cênicas do Sesc RJ). ${ }^{18}$

Vivemos caminhos coletivos de criação e sobrevivência de corpos, valores e desejos, mesmo lidando com muitas, esperadas e inesperadas dificuldades pessoais e institucionais. Aceitar e conseguir usufruir a câmera com público, conhecer e adaptar-se às exigências técnicas advindas da transformação da caixa preta cênica em caixa virtual das "peças-filmes" foram, e continuam sendo, os desafios de quem vive e acredita na arte como potência de vida. Orçamentos reduzidos por medidas provisórias decretadas, incluindo suspensão temporária de contratos de trabalho, equipes reduzidas, precariedade de equipamentos e de

${ }^{18}$ Entrevista concedida por e-mail, em 27/07/2021, como parte da pesquisa para compor este trabalho. 
sistemas adequados às produções artísticas e plataformas insuficientes para que as gravações fossem transmitidas com a qualidade necessária foram algumas das dificuldades que se somaram à impossibilidade dos encontros físicos entre todos os profissionais envolvidos.

Sem fronteiras geográficas e físicas, o trabalho dos analistas em pensar uma programação coerente e uníssona, onde todos eram responsáveis por todas as questões do Arte em Cena foi um exercício difícil, mas nos apresentou um panorama dos que realmente tem interesse e compromisso com a linguagem para qual foi contratado, daqueles que ainda precisam compreender melhor sua função dentro da Instituição. Outro fator positivo foi o maior alcance das programações, diversificação do público, ampliação dos dias e horários de programação, a atividade disponibilizada nas plataformas digitais após a realização, ao vivo, permitindo que o público pudesse ter acesso aos conteúdos a qualquer momento.

A produção dessas programações foi o grande desafio do projeto, pois é tudo ainda muito novo e a maioria dos artistas ainda não possui familiaridade com os recursos técnicos para esse tipo de transmissão, além da própria falta de estrutura oferecida pela Instituição. A cada nova realização, tivemos que pensar em estratégias a partir dos recursos técnicos dos contratados, principalmente dos artistas visuais, para apresentarem seus espaços criativos e seus processos de trabalho, muitas vezes sem iluminação necessária e captação de imagem e som adequadas para o local de onde transmitiam. (Depoimento de Stela Costa, Analista de Artes Visuais do SESC RJ). ${ }^{19}$

Foram experiências e continuam sendo vivências plenas de aprendizagens para nós, alguns trabalhadores do fazer artístico, sejam funcionários do SESC RJ, sejam produtores ou artistas envolvidos, e, também, para os diversos públicos que nos encontravam por intermédio das telas. Ampliamos e tecemos novas redes educativas, estabelecendo relações e usos diversos na comunicação, na curadoria, na produção, na fruição artística, na crítica e no fortalecimento dos elos culturais e artísticos que formamos e em que somos formados.

\section{REFERÊNCIAS}

ADICHIE, Chimamanda Ngozi. O perigo de uma história única. São Paulo: Companhia das Letras, 2019.

${ }^{19}$ Entrevista concedida por e-mail, em 28/07/2021, como parte da pesquisa para compor este trabalho. 
ALVES, Nilda. Práticas pedagógicas em imagens e narrativas: memórias de processos didáticos e curriculares para pensar as escolas hoje. São Paulo: Cortez, 2019.

ALVES, Nilda Guimarães; LIMA, Júlia da Silva; CONCEIÇÃO, Rafaela Rodrigues; GREGORIO, Talita Malheiros. SÓ AS ARTES NOS SALVAM!!!!! - as tantas crianças que há em nós. Revista Digital do LAV, Santa Maria, v. 14, n. 2, p. 158-72, maio/ago. 2021.

BAKHTIN, Mikhail. Estética da criação verbal. São Paulo: Martins Fontes, 2010.

CERTEAU, Michel. A invenção do cotidiano - 1. Artes de fazer. Petrópolis: Vozes, 2000.

DIDI-HUBERMAN, Georges. Sobrevivência dos vaga-lumes. Belo Horizonte: Ed. UFMG, 2011.

FERRAÇO, Carlos Eduardo.; SOARES, Maria da Conceição Silva.; ALVES, Nilda Guimarães. Michel de Certeau e as pesquisas nos/dos/com os cotidianos em educação. Rio de Janeiro: EdUERJ, 2018.

PELBARTL, Peter Pal. Da guerra civil. Arquivo Brasileiro de Psicologia, Rio de Janeiro, v. 70, n. especial, p. 190-8, 2018.

SOUSA DIAS. Lógica do acontecimento-Deleuze e a Filosofia. Porto: Afrontamento, [s.d.].

\section{Sobre os autores:}

Márcia Costa Rodrigues: Doutoranda na Universidade do Estado do Rio de Janeiro (UERJ). Mestre em Educação pela UERJ. Arquiteta pela Universidade Federal do Rio de Janeiro (UFRJ) e pedagoga pelo Instituto Isabel, RJ. Membro do Grupo de Pesquisa: Currículos Cotidianos - Redes Educativas, Imagens e Sons. Gerente de Cultura do Serviço Social do Comércio (SESC) Rio de janeiro. E-mail: marcia.rodrigues.rio@gmail.com, Orcid: http://orcid.org/0000-0002-3913-5901

Lúcia Teresa Romanholli: Doutoranda e mestre em Educação pela Universidade do Estado do Rio de Janeiro (UERJ). Pedagoga pela Universidade Federal do Estado do Rio de Janeiro (UNIRIO). Membro do Grupo de Pesquisa Currículos Cotidianos - Redes Educativas, Imagens e Sons. Professora da rede pública de ensino da cidade do Rio de Janeiro. E-mail: luciateresa@gmail.com, Orcid: https://orcid.org/0000-0002-1367-0789 
Cláudia Regina Ribeiro Pinheiro das Chagas: Doutora e mestre em Educação pela Universidade do Estado do Rio de Janeiro (UERJ). Pesquisadora com bolsa PNPD, CAPES/UERJ (2016-2021), no Grupo de Pesquisa Currículos Cotidianos Redes Educativas, Imagens e Sons, com exercício no PPGE Processos Formativos e Desigualdades Sociais/Faculdade de Formação de Professores/UERJ, São Gonçalo, RJ. Docente no Curso de Formação de Professores do Consórcio UERJ/CEDERJ. E-mail: chagas.prof@gmail.com, Orcid: https://orcid.org/0000-0001-5369-0875

Recebido em: 10/09/2021

Aprovado em: 15/10/2021 